\title{
Feingold syndrome type 2
}

INSERM

\section{Source}

INSERM. (1999). Orphanet: an online rare disease and orphan drug data base. Feingold syndrome type 2. ORPHA:391646

Feing old syndrome type 2 (FS2) is a rare inherited malformation syndrome characterized by skeletal abnormalities and mild intellectual disabilities similar to those seen in Feingold syndrome type 1 (FS1; see this term) but that lacks the manifestations of gastrointestinal atresia and short palpebral fissures. 